\title{
Correction: Investigation of synovial fluid induced Staphylococcus aureus aggregate development and its impact on surface attachment and biofilm formation
}

Matthew J. Pestrak, Tripti Thapa Gupta, Devendra H. Dusane, Doug V. Guzior, Amelia Staats, Jan Harro, Alexander R. Horswill, Paul Stoodley

The following information is missing from the Funding statement: ARH is supported by NIH public health service grant AI083211.

\section{Reference}

1. Pestrak MJ, Gupta TT, Dusane DH, Guzior DV, Staats A, Harro J, et al. (2020) Investigation of synovial fluid induced Staphylococcus aureus aggregate development and its impact on surface attachment and biofilm formation. PLoS ONE 15(4): e0231791. https://doi.org/10.1371/journal.pone.0231791 PMID: 32302361

\section{f OPEn ACCEss}

Citation: Pestrak MJ, Gupta TT, Dusane DH, Guzior DV, Staats A, Harro J, et al. (2020) Correction: Investigation of synovial fluid induced Staphylococcus aureus aggregate development and its impact on surface attachment and biofilm formation. PLOS ONE 15(5): e0233534. https://doi. org/10.1371/journal.pone.0233534

Published: May 14, 2020

Copyright: ๑ 2020 Pestrak et al. This is an open access article distributed under the terms of the Creative Commons Attribution License, which permits unrestricted use, distribution, and reproduction in any medium, provided the original author and source are credited. 